\title{
Iterative Synthesis of Oligo[n]Rotaxanes in Excellent Yield
}

\author{
James E. M. Lewis, ${ }^{\star, 1}$ Joby Winn, ${ }^{\star, 2}$ Luca Cera $^{2}$ and Stephen M. Goldup. ${ }^{1, *}$ \\ ${ }^{1}$ Chemistry, University of Southampton, Highfield, Southampton, SO17 1BJ, UK. \\ ${ }^{2}$ School of Biological Sciences, Queen Mary University of London, London E1 4NS, U.K.
}

ABSTRACT: We present an operationally simple iterative coupling strategy for the synthesis of oligomeric homo- and hetero[n]rotaxanes with precise control over the position of each macrocycle. The exceptional yield of the AT-CuAAC reaction, combined with optimized conditions that allow the rapid synthesis of the target oligomers, opens the door to the study of precisionengineered oligomeric interlocked molecules.

\section{- INTRODUCTION}

Main chain ${ }^{1}$ oligo- and poly-[n]rotaxanes typically consist of a linear axle component encircled by (n-1) macrocycles ${ }^{2}$ that are prevented from escaping by bulky end groups. ${ }^{3-6}$ The threaded arrangement of axle and rings gives rise to products with physical and chemical properties that are distinct from either component. As a result, poly[n]rotaxanes have been investigated for applications including drug delivery, ${ }^{7}$ electronic materials, ${ }^{8}$ stimuli-responsive materials ${ }^{9}$ and sensors, ${ }^{10}$ and the mechanical properties of so-called "slide ring gels" 11 have led to their commercial application in scratch resistant surfaces.

The vast majority of poly[n]rotaxanes studied to date are homocircuit ${ }^{12}$ structures, at least in part because many are synthesized using solvophobic threading which, although synthetically efficient, ${ }^{3}$ doesn't lend itself to the synthesis of heterocircuit targets. ${ }^{13-14}$ Solvophobic threading can also lead to poor control of the threading ratio, a measure of the degree of axle encapsulation. ${ }^{16}$ Conceptually, the simplest way to produce heterocircuit structures would be to design the axle with specific binding sites for each macrocycle. However, although poly[n]rotaxanes have been synthesized using such templating interactions, ${ }^{17}$ this approach is synthetically more challenging and has not yet been applied in the synthesis of heterocircuit systems. Thus, although the effect on poly[n]rotaxane properties of the threading ratio, which could be considered the mechanical analogue of the degree of polymerization, and macrocycle structure, the mechanical equivalent of monomer structure, have been investigated, ${ }^{3}$ to date little attention has been paid to the effect of the order of macrocycles in heterocircuit poly[n]rotaxanes, the mechanical analogue of monomer order in covalent polymers, currently a significant focus of research. ${ }^{18}$

Taking inspiration from the synthesis of information rich oligo-amides and oligo-nucleotides, ${ }^{19}$ one approach to gain complete control over structure in a main chain poly[n]rotaxane is the use of iterative coupling strategies to sequentially add macrocycles to the growing axle. ${ }^{20}$ Here we report the realization of such an iterative coupling methodology for the synthesis of oligo[n]rotaxanes with complete control over the order of macrocycles and excellent yield $(>89 \%)$ for each cycle of mechanical bond formation. We demonstrate the power of our approach through the synthesis of a homo[6]rotaxane and a hetero[4]rotaxane in excellent isolated yield.

\section{- RESULTS AND DISCUSSSION}

Iterative $\mathrm{Cu}$-mediated alkyne-azide cycloaddition (CuAAC) reactions $^{21}$ are an effective method for the synthesis of complex targets, ${ }^{22,23}$ including sequence-controlled oligomers, ${ }^{24}$ using a variety of methodologies ${ }^{25,26}$ due to the efficiency of the triazole-forming step. The active template CuAAC (AT$\mathrm{CuAAC}$ ) reaction, introduced by Leigh and co-workers, ${ }^{27}$ and modified by us to employ small macrocycles, ${ }^{28}$ is a similarly efficient method for the synthesis of interlocked structures. ${ }^{29,30}$ However, although the AT-CuAAC reaction often results in exceptionally high yields of interlocked molecules, reaction times often exceed $18 \mathrm{~h}$ and can be as long as $72 \mathrm{~h}$ for complete conversion, which is sub-optimal for iterative synthesis.

Optimization of the AT-CuAAC Reaction for Iterative Couplings. In order to optimize the conditions to shorten the reaction time, while maintaining the reaction yield, we first investigated the AT-CuAAC reaction of simple bis-alkyne $\mathbf{1}$. This also allowed us to assess whether the second AT-CuAAC reaction would proceed when the alkyne component was contained in an interlocked starting material, not a foregone conclusion by any means, and whether the presence of the second macrocyclic ligand would interfere with the $\mathrm{Cu}$-mediated bond formation. When the reaction between bis-alkyne 1, azide 2, and macrocycle 3 was carried out in $\mathrm{EtOH}$ with $\mathrm{N}^{i} \mathrm{Pr}_{2} \mathrm{Et}$ as a base, consumption of $\mathbf{3}$ was found to be complete in $2 \mathrm{~h}$ at $100{ }^{\circ} \mathrm{C}$ under microwave irradiation (Scheme 1). ${ }^{31} \mathrm{We}$ initially anticipated that a mixture of [2] rotaxane 5 and [3] rotaxane 6 would be formed, in keeping with the outcome of the corresponding reaction in the absence of the macrocycle 3 which produces a statistical mixture of di-yne 1, mono- and bistriazole products. However, ${ }^{1} \mathrm{H}$ NMR analysis of the product mixture after aqueous work up revealed two major products, [2]rotaxane $\mathbf{5}$ and a second, singly interlocked product which was tentatively identified as interlocked $\mathrm{Cu}$ triazolide $4 .^{28 \mathrm{~b}}$ Repeating the same reaction at room temperature gave $\mathbf{4}$ as the sole interlocked product and allowed it to be identified unambiguously by ${ }^{1} \mathrm{H}$ NMR (Figure $1 \mathrm{~b}$ ) and mass spectrometry $(\mathrm{m} / \mathrm{z}$ =958). 
Scheme 1. Iterative synthesis of [3]Rotaxane $6^{a}$

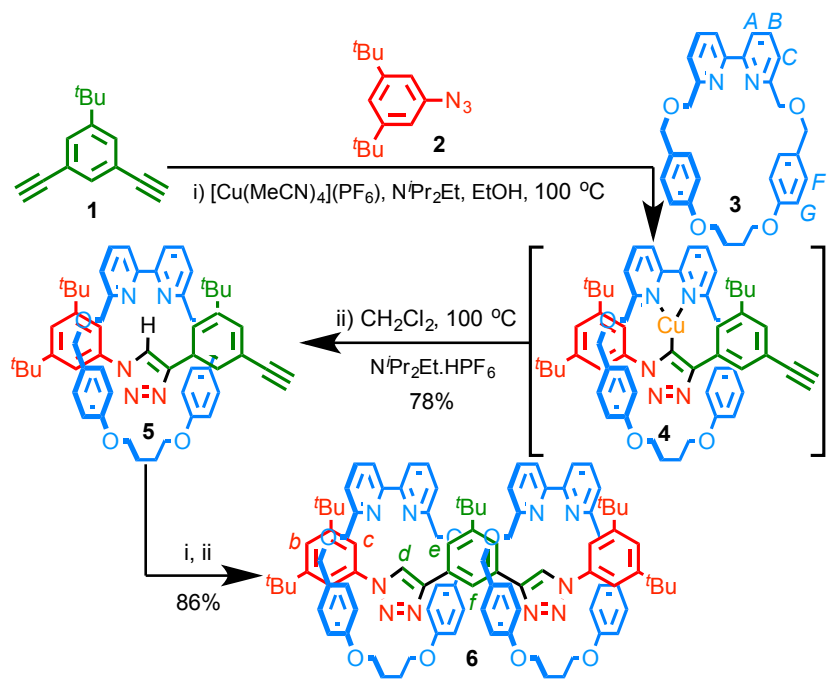

Reagents and conditions: i) 1 equiv. each 1, 2, 3, and $\left[\mathrm{Cu}(\mathrm{MeCN})_{4}\right] \mathrm{PF}_{6}, \mathrm{EtOH}, 100{ }^{\circ} \mathrm{C}(\mu \mathrm{W}), 2 \mathrm{~h}$; ii) $\mathrm{CH}_{2} \mathrm{Cl}_{2}, 100$ ${ }^{\circ} \mathrm{C}(\mu \mathrm{W}), 1 \mathrm{~h}$.
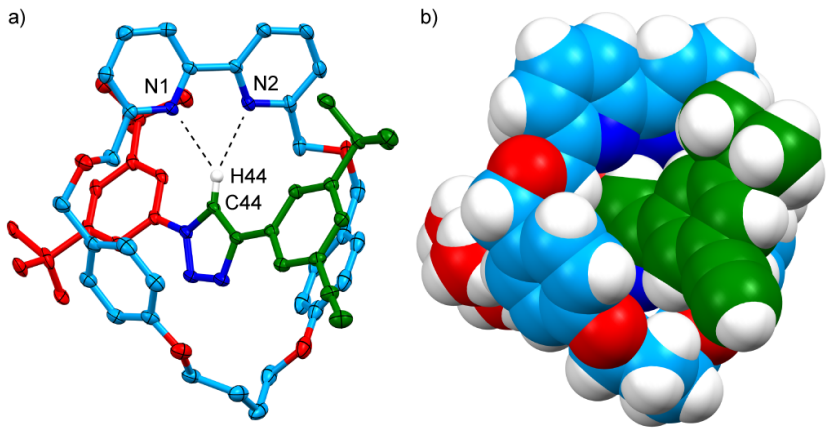

Figure 1. Solid state structure of [2]rotaxane 5 in a) ellipsoid and b) spacefilling representation. Interaction lengths $(\AA)$ and angles

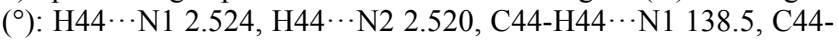
$\mathrm{H} 44 \cdots \mathrm{N} 2154.8$.

The high selectivity observed in the production of $\mathbf{5}$ is intriguing but potentially problematic as the same steric shielding of the acetylene moiety could to lead to poor efficiency or the need for longer reaction times in the second round of ATCuAAC. Indeed, initial attempts to couple $\mathbf{5}$ with azide $\mathbf{2}$ and macrocycle $\mathbf{3}$ under the same AT-CuAAC conditions with sufficient $\mathrm{Cu}^{\prime}$ to coordinate to macrocycle $\mathbf{3}$ and rotaxane $\mathbf{5}$ produced a poor yield of [3] rotaxane $\mathbf{6}$ with the balance of material made up by the reaction of azide $\mathbf{2}$ and alkyne $\mathbf{5}$ to give the bis-triazole axle encircled by a single macrocycle. Working from the hypothesis that the steric hindrance of $\mathbf{5}$ might be exacerbated by the re-coordination of $\mathrm{Cu}^{\prime}$ into the macrocycle cavity, we repeated the AT-CuAAC reaction without additional $\mathrm{Cu}$ ' over and above that required to coordinate with macrocycle 3 . Pleasingly, under these conditions the second mechanical bond formed efficiently and, after reprotonation of the corresponding triazolide byproduct by heating in $\mathrm{CH}_{2} \mathrm{Cl}_{2}$, [3] rotaxane 6 was isolated in $86 \%$ yield. Thus, under our optimized conditions over two steps, two equivalents of azide $\mathbf{2}$ and macrocycle $\mathbf{3}$ were combined with bis-alkyne $\mathbf{1}$ to produce a doubly interlocked [3] rotaxane in $67 \%$ yield.
Analysis of Rotaxane 6. Triazolide 4, [2]rotaxane 5 and [3] rotaxane 6 all display characteristic shifts in their ${ }^{1} \mathrm{H}$ NMR spectra (Figure 2b, 2c and $2 \mathrm{~d}$ respectively) consistent with their interlocked structure. In particular, as with all rotaxanes derived from $3,{ }^{28 a}$ protons $\mathrm{H}_{F}$ and $\mathrm{H}_{G}$ of the macrocycle (Figure $2 \mathrm{a}$ ) appear at lower ppm than the non-interlocked macrocycle and the triazole $\mathrm{C}-\mathrm{H}$ signals in $\mathbf{5}$ and $\mathbf{6}$ resonate at higher $\operatorname{ppm}(\Delta \delta=2.33$ and $2.22 \mathrm{ppm}$ respectively) than the noninterlocked axle, consistent with the presence of a $\mathrm{C}-\mathrm{H} \cdots \mathrm{N}$ hydrogen bond, as observed in the solid state structure of $\mathbf{5}$.

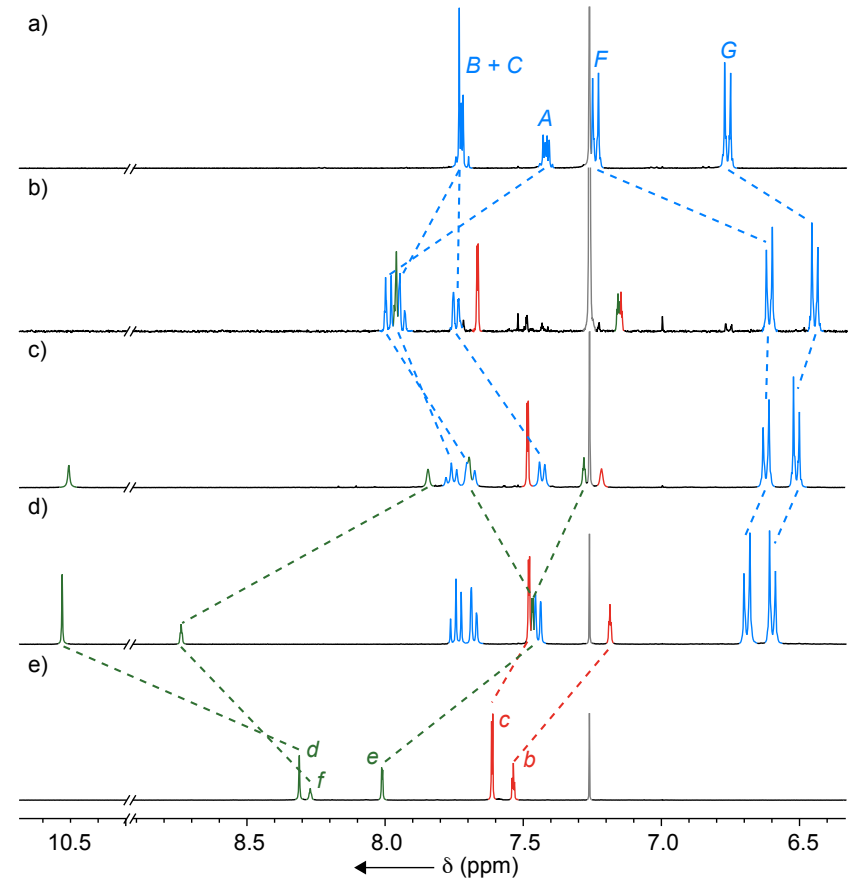

Figure 2. Partial ${ }^{1} \mathrm{H} \mathrm{NMR}\left(400 \mathrm{MHz}, \mathrm{CDCl}_{3}, 298 \mathrm{~K}\right)$ with selected signals assigned of a) macrocycle 3 ; b) crude reaction mixture containing triazolide 4 as the major product $(>95 \%)$ c) [2]rotaxane 5; d) [3]rotaxane 6; e) corresponding non-interlocked axle of [3] rotaxane 6. For macrocycle and axle labeling, see Scheme 1 (axle labeling as in 6).

Formation of the second mechanical bond to produce $\mathbf{6}$ increases the symmetry of the molecule, resulting in fewer signals for the axle component compared with $\mathbf{5}$. More unexpectedly, proton $\mathrm{H}_{f}$ of the axle resonates $0.46 \mathrm{ppm}$ higher in rotaxane 6 than in the non-interlocked axle (Figure 2e) and protons $\mathrm{H}_{e}$ resonate $0.56 \mathrm{ppm}$ lower. This is surprising considering the absence of similar effects or obvious non-covalent interactions between the macrocycle and equivalent protons in the solidstate structure of rotaxane 5 (Figure 1). Computational modeling $^{32}$ of the non-interlocked axle suggested that the shielding of $\mathrm{H}_{e}$ and the deshielding of $\mathrm{H}_{f}$ may both be the result of conformational changes enforced by the sterically crowded mechanical bond; the predicted chemical shifts of protons $\mathrm{H}_{e}$ and $\mathrm{H}_{f}$ vary considerably depending on the relative orientation of the central benzene ring and the triazole moieties.

Previous reports ${ }^{23 e, h}$, and molecular modeling ${ }^{32}$ suggest that the non-interlocked axle adopts a range of conformations about the central benzene ring in which the syn-syn conformer is disfavored. ${ }^{33}$ Conversely, the observed shielding of $\mathrm{H}_{e}$ and deshielding of $\mathrm{H}_{f}$ in rotaxane 6 compared with the non- 
interlocked axle is consistent with the syn-syn rotamer being favored in the case of the [3]rotaxane. In keeping with this proposal, NOESY NMR analysis (see ESI) of $\mathbf{6}$ reveals strong cross-peaks between $\mathrm{H}_{d}$ and $\mathrm{H}_{e}$ but only a weak correlation between $\mathrm{H}_{d}$ and $\mathrm{H}_{f}$ (see supporting information). Models of 6 (Figure 3) indicate that steric interactions between the macrocycles are minimized in this conformation. ${ }^{32}$ Thus, based on NMR analysis molecular modeling it appears that the sterically crowded nature of the mechanical bond stabilizes the synsyn rotamer of [3] rotaxane 6 leading to an unusual extended conformation in solution.

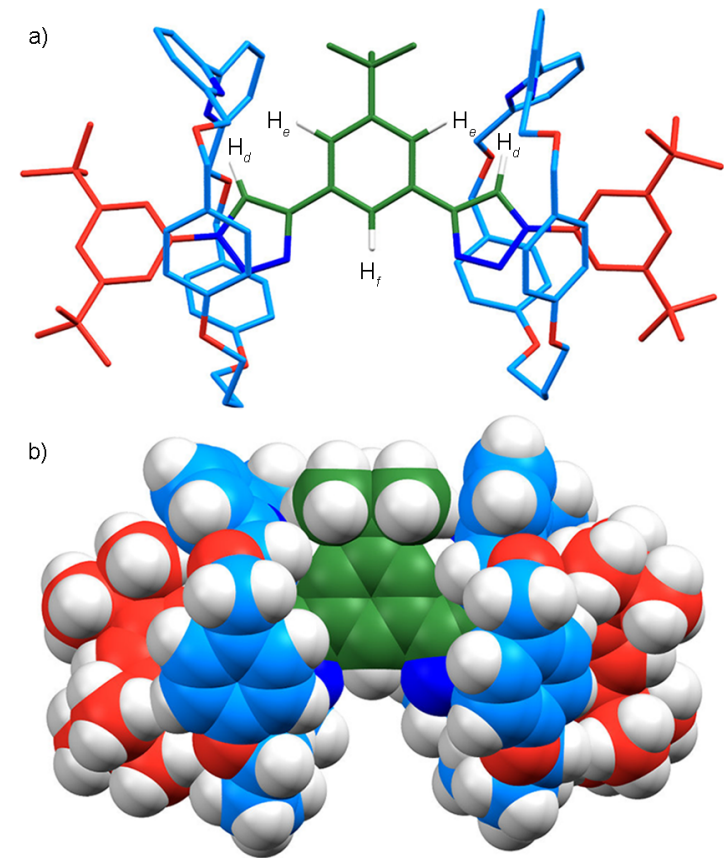

Figure 3. Computer model (PM6) of the proposed preferred synsyn rotamer of [3]rotaxane 6 in a) sticks and b) spacefilling representations.

Iterative AT-CuAAC Synthesis of a Homo[6]Rotaxane. In order to apply the conditions developed above to the iterative synthesis of oligomeric rotaxanes we synthesized building block $\mathbf{8}$ that incorporates an azide and a protected acetylene moiety. ${ }^{25 b, d}$ When alkyne 7 and azide $\mathbf{8}$ were subjected to our optimized AT-CuAAC conditions macrocycle $\mathbf{3}$ was quantitatively converted into a mixture of [2] rotaxane 9 and the corresponding $\mathrm{Cu}^{\prime}$ triazolide (Scheme 2). Heating the crude AT$\mathrm{CuAAC}$ product in $\mathrm{CH}_{2} \mathrm{Cl}_{2}$ led to protonolysis of the $\mathrm{Cu}-\mathrm{C}$ bond. Subsequent TBAF-mediated protodesilylation acetylene moiety produced [2] rotaxane 9 which was isolated in $94 \%$ yield over three steps in one pot, requiring a total of $4 \mathrm{~h}$ reaction time. Repeating this sequence iteratively gave, in order, [3] rotaxane $10(94 \%)$; [4]rotaxane $11(91 \%)$; [5]rotaxane 12 (90\%) and finally [6]rotaxane $13(92 \%)$ without any significant loss of reaction efficiency. The yield of the final product was $67 \%$ over 15 steps with 5 rounds of purification to form 5 new mechanical bonds.

${ }^{1} \mathrm{H}$ NMR analysis confirmed the homogeneity of the isolated oligomeric products (Figure 4). As in rotaxanes 5 and $\mathbf{6}$, triazole proton $\mathrm{H}_{d}$ of [2]rotaxane 9 resonates at $>10 \mathrm{ppm}$ (Figure $4 a)$, suggesting hydrogen bonding interactions with the bipyridine of the macrocycle, as observed in the solid state structure of 5 (Figure 1), are also present in 9. Similarly, protons $\mathrm{H}_{F}$ and $\mathrm{H}_{G}$ of the flanking aromatic moieties are shifted to lower ppm in the interlocked structure. Introduction of the second macrocycle to give [3] rotaxane $\mathbf{1 0}$ (Figure 4b) leads to the appearance of a second distinct triazole signal at high ppm and another set of flanking aromatic protons between 6.6 and 6.9 ppm. Formation of the second mechanical bond led to a triplet at $8.7 \mathrm{ppm}$, which was assigned as proton $\mathrm{H}_{g}$ of the axle. Subsequent iterations lead to distinct signals for the triazole, flanking aromatic rings of the macrocycle and the ortho proton of the linking benzene ring up until [6]rotaxane $\mathbf{1 3}$ (Figure 4e), where some signals become isochronous, indicating a transition from discrete proton environments to more oligomerictype behavior.

The high chemical shifts of protons $\mathrm{H}_{g}, \mathrm{H}_{l}, \mathrm{H}_{q}$ and $\mathrm{H}_{v}$, suggest that, as in [3] rotaxane 6, [6]rotaxane $\mathbf{1 3}$ adopts a preferred conformation where the triazole rings are oriented with their $\mathrm{N}$-atoms syn-periplanar to the central ortho proton of the linking aromatic units. ROESY NMR analysis of $\mathbf{1 3}$ is consistent with this proposal; weak correlations were observed between the central aromatic $\mathrm{CH}$ and the neighboring triazole protons and strong correlations with the other $\mathrm{C}-\mathrm{H}$ residues of the linking aromatic rings. Inspection of molecular models ${ }^{32}$ once again suggests that this arrangement minimizes steric interactions between adjacent macrocycles. This leads to an extended conformation of the axle component and an end-to-end distance of $\sim 3.8 \mathrm{~nm}$. In contrast, previously reported meta-linked phenyl-triazole oligomers are reported to adopt either helical conformations to maximize $\mathrm{H}$-bonding and $\pi-\pi$ stacking, ${ }^{23 \mathrm{f}, \mathrm{h}}$ or alternating $s y n$-anti conformations ${ }^{23 \mathrm{e}, \mathrm{h}}$ to minimize dipoledipole interactions between adjacent polarized triazole moieties. 
Scheme 2. Iterative AT-CuAAC Synthesis of Oligo[n]rotaxanes. ${ }^{a}$

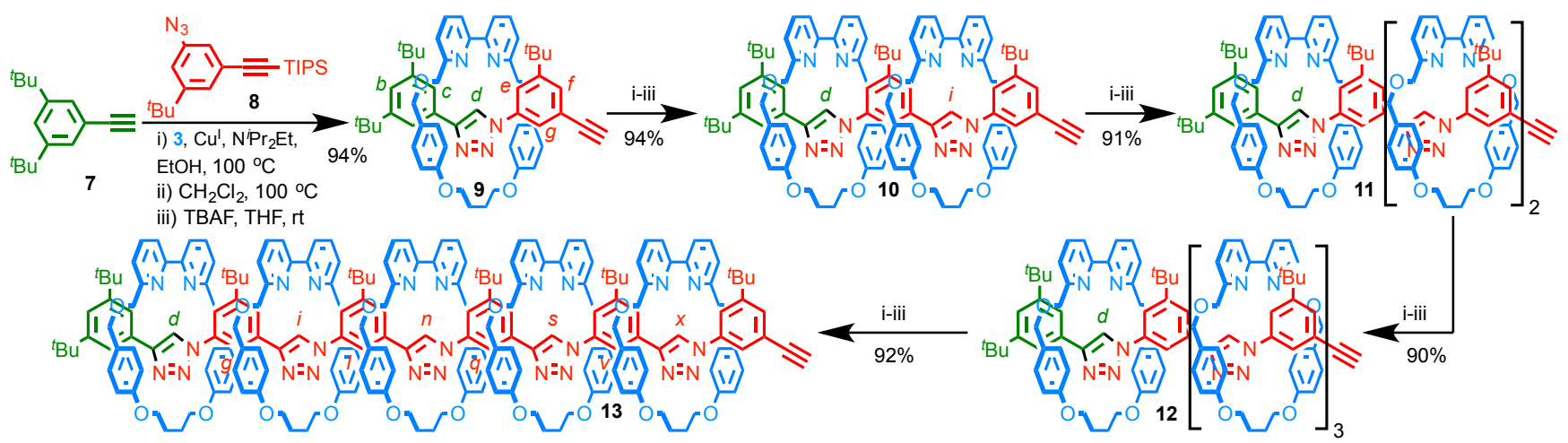

${ }^{a}$ Reagents and conditions: i) 1 equiv. 1, 2, 3 and $\left[\mathrm{Cu}(\mathrm{MeCN})_{4}\right] \mathrm{PF}_{6}, \mathrm{EtOH}, 100{ }^{\circ} \mathrm{C}(\mu \mathrm{W}), 2 \mathrm{~h}$; ii) $\mathrm{CH}_{2} \mathrm{Cl}_{2}, 100{ }^{\circ} \mathrm{C}(\mu \mathrm{W}), 1 \mathrm{~h}$; iii) $\mathrm{TBAF}$, THF, rt, $1 \mathrm{~h}$.

a)
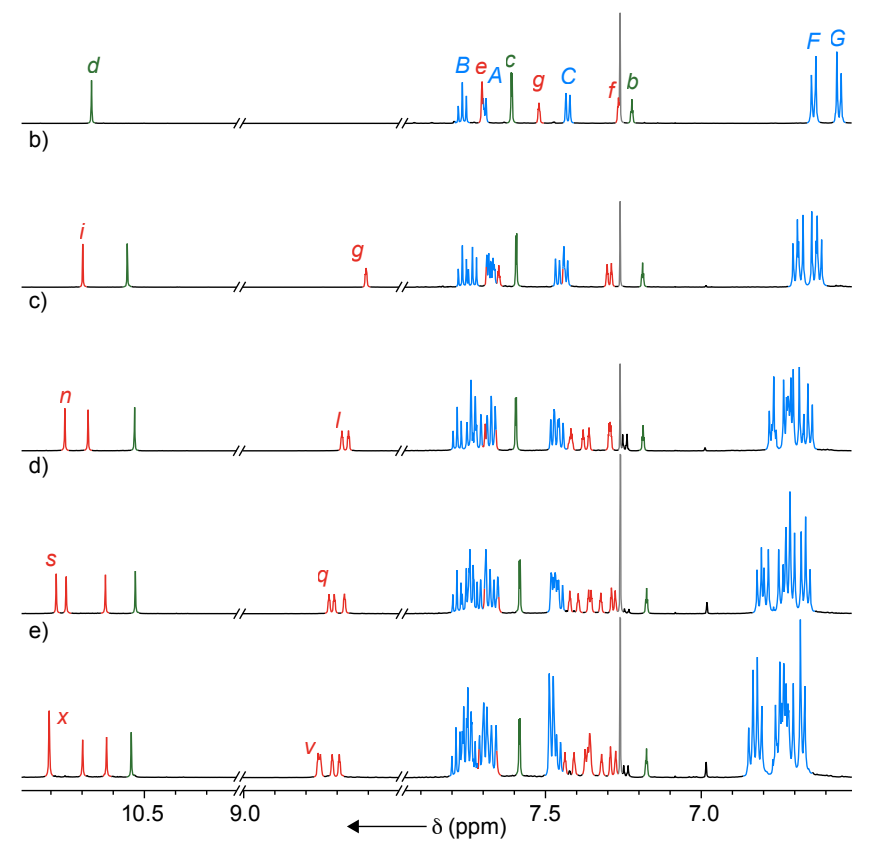

Figure 4. Partial ${ }^{1} \mathrm{H}$ NMR $\left(500 \mathrm{MHz}, \mathrm{CDCl}_{3}, 298 \mathrm{~K}\right)$ with selected signals assigned ${ }^{34}$ of a) [2] rotaxane 9 ; b) [3]rotaxane 10 ; c) [4]rotaxane 11; d) [5]rotaxane 12; a) [6]rotaxane 13. For macrocycle and axle labeling, see Schemes 1 and 2 respectively.

Iterative Synthesis of a Hetero[4]Rotaxane. Having demonstrated the iterative AT-CuAAC synthesis of homo [n]rotaxanes, we turned our attention to the synthesis of a heterocircuit analogue with precise control over the order of the different macrocycles. Reaction of macrocycle 14 with alkyne 7 and azide 8 (Scheme 3) resulted in quantitative conversion to the corresponding triazolide. In this case, heating the crude reaction product in $\mathrm{CH}_{2} \mathrm{Cl}_{2}$ did not lead to protonation of the $\mathrm{Cu}-\mathrm{C}$ bond, presumably due to the more hindered environment provided by macrocycle 14 . As macrocycle 14 is stable to acidic conditions, TFA was employed to effect the required protodemetallation. Subsequent protodesilylation of the crude product with TBAF gave target [2] rotaxane $\mathbf{1 5}$ in $90 \%$ isolated yield over three chemical steps.
The lack of rotational symmetry in macrocycle 14 results in a more complicated ${ }^{1} \mathrm{H}$ NMR spectrum (Figure $5 \mathrm{~b}$ ) than that of [2] rotaxanes 6 and 9, although the broad features (low field triazole proton $\mathrm{H}_{d}$, shielded flanking aromatic protons $\mathrm{H}_{G}, \mathrm{H}_{H}$, $\mathrm{H}_{P}$ and $\mathrm{H}_{Q}$ ) remain the same. Also it is noteworthy that, as macrocycle $\mathbf{1 4}$ is rotationally unsymmetrical and the thread is translationally unsymmetrical, [2]rotaxane $\mathbf{1 5}$ is mechanically planar chiral, ${ }^{28 \mathrm{c}}$ albeit formed as a racemic mixture. Indeed, single crystal x-ray analysis (Figure 6) revealed that the unit cell contains both enantiomers of $\mathbf{1 5}$, related by a center of inversion.

Scheme 3. Synthesis of Hetero[4]Rotaxane 18.

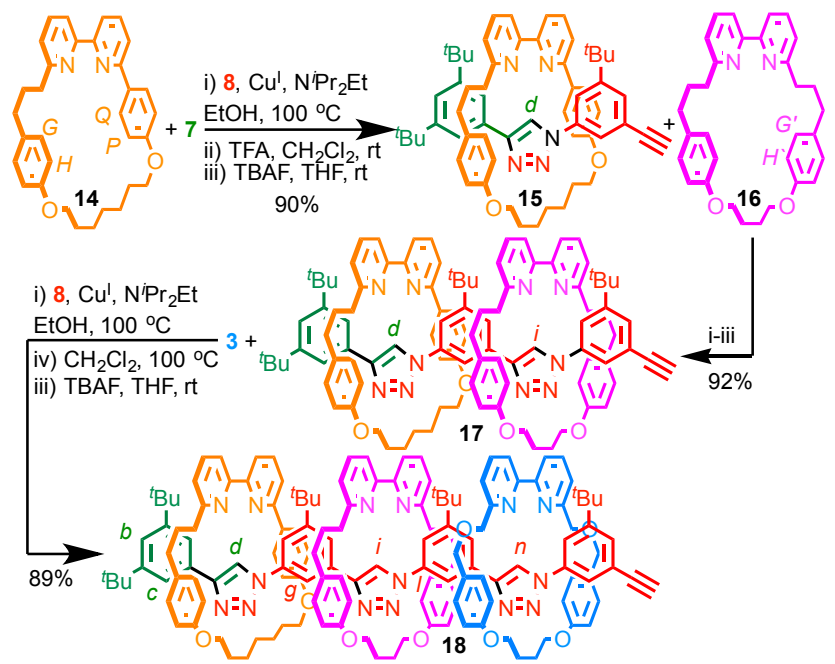

${ }^{a}$ Reagents and conditions: i) 1 equiv. 1, 2, 3, and $\left[\mathrm{Cu}(\mathrm{MeCN})_{4}\right] \mathrm{PF}_{6}, \mathrm{EtOH}, 100{ }^{\circ} \mathrm{C}(\mu \mathrm{W}), 2 \mathrm{~h}$; ii) $\mathrm{TFA}, \mathrm{CH}_{2} \mathrm{Cl}_{2}, \mathrm{rt}$, $1 \mathrm{~h}$; iii) TBAF, THF, rt, $1 \mathrm{~h}$; iv) $\mathrm{CH}_{2} \mathrm{Cl}_{2}, 100{ }^{\circ} \mathrm{C}(\mu \mathrm{W}), 1 \mathrm{~h}$. 


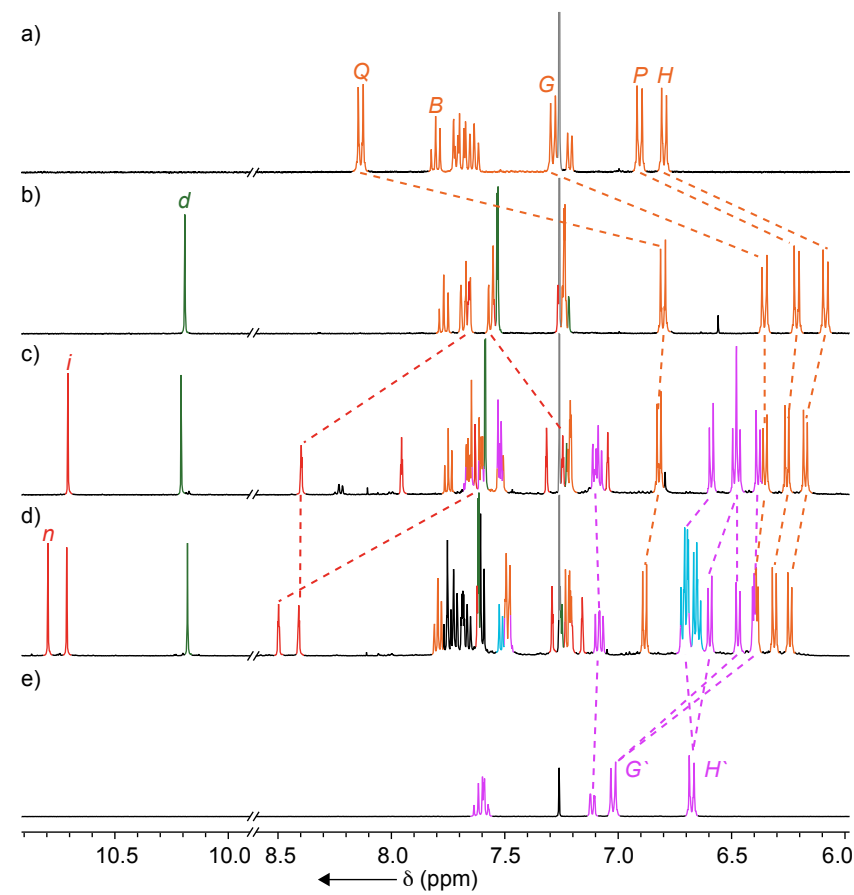

Figure 5. Partial ${ }^{1} \mathrm{H}$ NMR (500 MHz, $\mathrm{CDCl}_{3}, 298 \mathrm{~K}$ ) with selected signals assigned ${ }^{34}$ of a) [2]rotaxane 15 ; b) [3]rotaxane 17 ; c) [4]rotaxane 18. For labeling see Scheme 3.

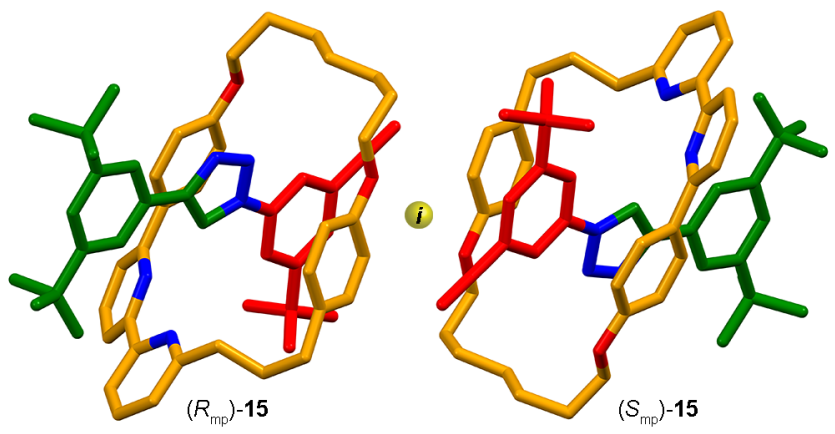

Figure 6. Solid state structure of [2] rotaxane $\mathbf{1 5}$ showing both enantiomers of the mechanically chiral interlocked structures in the unit cell, related by the point of inversion $(i)$.

As the axle of [2]rotaxane 15 lacks prochiral units, which would be rendered diastereotopic in the interlocked structure, the chirality of $\mathbf{1 5}$ is not apparent in the ${ }^{1} \mathrm{H}$ NMR spectrum. However, it makes itself known when the second macrocycle is introduced. Using the same reaction sequence, [2]rotaxane 15 was converted into [3] rotaxane 17 by reaction with macrocycle $\mathbf{1 6}$ and azide $\mathbf{8}$ in excellent $92 \%$ yield. Despite being bilaterally symmetric, in [3] rotaxane $\mathbf{1 7}$ the mirror symmetry of macrocycle $\mathbf{1 6}$ is broken by the element of mechanical stereochemistry and thus protons which are equivalent in the non-interlocked precursor are now diastereotopic and in principle may appear as non-equivalent in the ${ }^{1} \mathrm{H}$ NMR. This is most clearly demonstrated in the case of protons $\mathrm{H}_{G}$ " and $\mathrm{H}_{H}$ of the flanking aromatic units which appear as two sets of two coupled doublets and protons $\mathrm{H}_{C^{*}}$ which appear as two overlapping doublets.
Similar effects are observed in [4] rotaxane $\mathbf{1 8}$ which was produced in an excellent $89 \%$ yield by reaction of [3]rotaxane 17 with macrocycle 3 and azide 8. ${ }^{1} \mathrm{H}$ NMR analysis of [4]rotaxane $\mathbf{1 7}$ (Figure 5d) revealed that not only are many of the resonances of macrocycle $\mathbf{1 6}$ non-equivalent, even signals arising from macrocycle $\mathbf{3}$ show evidence of desymmetrization by the element of mechanical chirality with protons $\mathrm{H}_{F}$ " and $\mathrm{H}_{G}$ " appearing as complex multiplets. Although chiral information transfer over long distances in covalently bonded systems, typically through conformational biasing, ${ }^{35}$ has previously been observed, the transfer of the mechanical stereochemical information centered on macrocycle $\mathbf{1 4}$ through the mechanical bond to macrocycle $\mathbf{1 6}$ is extremely unusual; in the case of [4]rotaxane $\mathbf{1 8}$ molecular models ${ }^{32}$ suggest a distance of $1.3 \mathrm{~nm}$ between the element of mechanical chirality and macrocycle 3 , assuming the axle adopts a syn-syn orientations consistent with ROESY NMR analysis and the low-field shift of protons $\mathrm{H}_{g}$ " and $\mathrm{H}_{/}$.

\section{- CONCLUSIONS}

In summary we have successfully demonstrated an iterative AT-CuAAC approach for the high-yielding ( $90 \%$ per mechanical bond) synthesis of both homo- and hetero [n]rotaxanes. With regards to the latter, our iterative coupling approach allowed us to install three different macrocycles on the axle with their order determined simply by the order in which the coupling reactions were carried out. Based on NMR analysis, supported by molecular modeling, the sterically crowded nature of the mechanical bond in the [n]rotaxane structures favors an unusual all-syn geometry of the axle component to minimize steric repulsion between the macrocycles, resulting in an extended conformation. With high yielding and operationally convenient conditions in hand, it is now possible to synthesize oligo[n]rotaxanes rapidly with control over the structure of the axle (by varying the azide-acetylene monomer) and macrocycle. Furthermore, by electing to omit the macrocycle in some coupling steps, the threading ratio of the oligomeric product can be controlled precisely. Future work will focus on transferring the reaction to the solid phase to allow the automated synthesis of longer oligomers with precise control of their structure without the need for costly and timeconsuming purification steps,${ }^{36}$ allowing designer oligo- and poly-[n]rotaxanes to be investigated for a variety of applications. ${ }^{37}$ Work towards this goal is currently taking place in our laboratory.

\section{- ASSOCIATED CONTENT}

\section{Supporting Information}

Full experimental details and characterization data for all novel compounds. Crystallographic data for rotaxanes 5 and 15. This material is available free of charge via the Internet at http://pubs.acs.org. 


\section{Corresponding Author}

*s.goldup@soton.ac.uk

\section{Author Contributions}

These authors contributed equally.

\section{- ACKNOWLEDGMENT}

The authors are grateful to Fluorochem for the gift of reagents. High-resolution mass spectrometry analysis was carried out by the EPSRC National Spectrometry Facility. This work was supported financially by the Royal Society, the European Union and the EPSRC (EP/J01981X/1). This project has received funding from the European Union's Horizon 2020 research and innovation programme under the Marie Sklodowska-Curie grant agreement No 660731. J.E.M.L. is an EU Marie Skłodowska-Curie Fellow. S.M.G. is a Royal Society Research Fellow.

\section{- REFERENCES}

(1) Other classes of polyrotaxanes include side chain, mechanically linked and pseudorotaxane structures. For selected examples of these see refs 4,5 and 6 respectively.

(2) Although this is the most common class of main chain poly[n]rotaxanes, alternative structures exist such as polymers of macrocycles that are threaded by multiple axles. ${ }^{3}$ For selected examples of multiply-threaded discrete rotaxanes see: (a) Klotz, E. J. F.; Claridge, T. D. W.; Anderson, H. L. J. Am. Chem. Soc. 2006, 128, 15374. (b) Prikhod'ko, A. I.; Sauvage, J.-P. J. Am. Chem. Soc. 2009, 131, 6794. (c) Cheng, H. M.; Leigh, D. A.; Maffei, F.; McGonigal, P. R.; Slawin, A. M. Z.; Wu, J. J. Am. Chem. Soc. 2011, 133, 12298. (d) Inouye, M.; Hayashi, K.; Yonenaga, Y.; Itou, T.; Fujimoto, K.; Uchida, T.; Iwamura, M.; Nozaki, K. Angew. Chem. Int. Ed. 2014, 53, 14392. (e) Danon, J. J.; Leigh, D. A.; McGonigal, P. R.; Ward, J. W.; Wu, J. J. Am. Chem. Soc. 2016, DOI: 10.1021/jacs.6b07733.

(3) For selected reviews on polyrotaxanes and related structures see: (a) Takata, T. Polym. J. 2006, 38, 1; (b) Araki, J.; Ito, K. Soft Matter 2007, 3, 1456; (c) Harada, A.; Hashidzume, A.; Yamaguchi, H.; Takashima, Y. Chem. Rev. 2009, 109, 5974; (d) Appel, E. A..; del Barrio, J.; Loh, X. J.; Scherman, O. A. Chem. Soc. Rev. 2012, 41, 6195. (e) Avestro, A.-J.; Belowich, M. E.; Stoddart, J. F. Chem. Soc. Rev. 2012, 41, 5881. (f) Arunachalam, M.; Gibson, H. W. Prog. Polym. Sci. 2014, 39, 1043; (g) Garcia-Rio, L.; Otero-Espinar, F.; Luzardo-Alvarez, A.; Blanco-Mendez, J. Current Topics in Medicinal Chemistry 2014, 478; (h) Harada, A.; Takashima, Y.; Nakahata, M. Acc. Chem. Res. 2014, 47, 2128. (i) Wei, P.; Yan, X.; Huang, F. Chem. Soc. Rev. 2015, 44, 815.

(4) For selected examples of side chain polyrotaxanes see: (a) Born, M.; Ritter, H. Angew. Chem. Int. Ed. English 1995, 34, 309. (b) Yu, G.; Suzaki, Y.; Abe, T.; Osakada, K. Dalt. Trans. 2013, 42, 1476. (c) Suzuki, S.; Ishiwari, F.; Nakazono, K.; Takata, T. Chem. Commun. 2012, 48, 6478. (d) Bria, M.; Bigot, J.; Cooke, G.; Lyskawa, J.; Rabani, G.; Rotello, V. M.; Woisel, P. Tetrahedron 2009, 65, 400. (e) Sun, S.; Hu, X.-Y.; Chen, D.; Shi, J.; Dong, Y.; Lin, C.; Pan, Y.; Wang, L. Polym. Chem. 2013, 4, 2224.

(5) For selected examples of threaded supramolecular polymers and poly-pseudorotaxanes see: (a) Mercer, D. J.; Vukotic, V. N.; Loeb, S. J. Chem. Commun. 2011, 47, 896; (b) Ogoshi, T.; Kayama, H.; Yamafuji, D.; Aoki, T.; Yamagishi, T. Chem. Sci. 2012, 3, 3221; (c) Ji, X.; Dong, S.; Wei, P.; Xia, D.; Huang, F. Adv. Mater. 2013, 25, 5725; (d) Li, C.; Han, K.; Li, J.; Zhang, Y.; Chen, W.; Yu, Y.; Jia, X.
Chem. Eur J. 2013, 11892; (e) Massoudi, A.; Adeli, M.; Khosravi far, L. Int. J. Polym. Sci. 2014, 2014, 1; (f) Huang, Z.; Yang, L.; Liu, Y.; Wang, Z.; Scherman, O. A.; Zhang, X. Angew. Chem. Int. Ed. 2014, 53, 5351; (g) Noor, A.; Moratti, S. C.; Crowley, J. D. Chem. Sci. 2014, 5, 4283; (h) Wei, P.; Yan, X.; Cook, T. R.; Ji, X.; Stang, P. J.; Huang, F. ACS Macro Lett. 2016, 671; (i) Chen, D.; Zhan, J.; Zhang, M.; Zhang, J.; Tao, J.; Tang, D.; Shen, A.; Qiu, H.; Yin, S. Polym. Chem. 2015, 6, 25; (j) Gao, L.; Zheng, B.; Chen, W.; Schalley, C. A. Chem. Commun. 2015, 51, 14901; (k) Shi, Y.; Yang, Z.; Liu, H.; Li, Z.; Tian, Y.; Wang, F. ACS Macro Lett. 2015, 4, 6; (1) Zhang, W.; Zhang, H.-Y.; Zhang, Y.-H.; Liu, Y. Chem. Commun. 2015, 51, 16127.

(6) For selected examples of mechanically linked polymeric structures see: (a) Li, S.; Zheng, B.; Chen, J.; Dong, S.; Ma, Z.; Huang, F.; Gibson, H. W. J. Polym. Sci. Part A Polym. Chem. 2010, 48, 4067. (b) Hmadeh, M.; Fang, L.; Trabolsi, A.; Elhabiri, M.; Albrecht-Gary, A.-M.; Stoddart, J. F. J. Mater. Chem. 2010, 20, 3422. (c) Wei, P.; Yan, X.; Huang, F. Chem. Commun. 2014, 50, 14105; (d) Aoki, D.; Uchida, S.; Takata, T. ACS Macro Lett. 2014, 3, 324. (e) Aoki, D.; Uchida, S.; Takata, T. Angew. Chem. Int. Ed. 2015, 54, 6770; (f) Cao, P.-F.; Mangadlao, J. D.; de Leon, A.; Su, Z.; Advincula, R. C. Macromolecules 2015, 48, 3825; (g) Shi, Y.; Yang, Z.; Liu, H.; Li, Z.; Tian, Y.; Wang, F. ACS Macro Lett. 2015, 4, 6. (h) Nisar Ahamed, B.; Duchêne, R.; Robeyns, K.; Fustin, C.-A. Chem. Commun. 2016, 52, 2149.

(7) For selected examples of main chain poly[n]rotaxanes for biomedical applications see: (a) Li, J.; Li, X.; Zhou, Z.; Ni, X.; Leong, K. W. Macromolecules 2001, 34, 7236; (b) Li, J. J. Drug Deliv. Sci. Technol. 2010, 20, 399; (c) Li, J. J.; Zhao, F.; Li, J. Appl. Microbiol. Biotechnol. 2011, 90, 427; (d) Yu, S.; Zhang, Y.; Wang, X.; Zhen, X.; Zhang, Z.; Wu, W.; Jiang, X. Angew. Chem. Int. Ed. 2013, 52, 7272; (e) Loh, X. J. Mater. Horizons 2014, 1, 185. (f) Tamura, A.; Yui, N. J. Biol. Chem. 2015, 290, 9442.

(8) For selected examples of rotaxane insulated molecular wires see: (a) Taylor, P.; O'Connell, M.; McNeill, L.; Hall, M.; Aplin, R.; Anderson, H. Angew. Chem. Int. Ed. Engl. 2000, 39, 3456; (b) Brovelli, S.; Latini, G.; Frampton, M. J.; McDonnell, S. O.; Oddy, F. E.; Fenwick, O.; Anderson, H. L.; Cacialli, F. Nano Lett. 2008, 8, 4546; (c) Frampton, M. J.; Sforazzini, G.; Brovelli, S.; Latini, G.; Townsend, E.; Williams, C. C.; Charas, A.; Zalewski, L.; Kaka, N. S.; Sirish, M.; Parrott, L. J.; Wilson, J. S.; Cacialli, F.; Anderson, H. L. Adv. Funct. Mater. 2008, 18, 3367; (d) Mróz, M. M.; Lanzani, G.; Virgili, T.; Mc Donnell, S. O.; Frampton, M. J.; Anderson, H. L. Phys. Rev. B - Condens. Matter Mater. Phys. 2009, 80, 1; (e) Terao, J.; Tsuda, S.; Tanaka, Y.; Okoshi, K.; Fujihara, T.; Tsuji, Y.; Kambe, N. J. Am. Chem. Soc. 2009, 131, 16004; (f) Oddy, F.; Brovelli, S.; Stone, M.; Klotz, E.; Cacialli, F.; Anderson, H. J. Mater. Chem. 2009, 19, 2846; (g) Brovelli, S.; Virgili, T.; Mroz, M. M.; Sforazzini, G.; Paleari, A.; Anderson, H. L.; Lanzani, G.; Cacialli, F. Adv. Mater 2010, 22, 3690; (h) Masai, H.; Terao, J.; Tsuji, Y. Tetrahedron Lett. 2014, 55, 4035; (i) Masai, H.; Terao, J.; Makuta, S.; Tachibana, Y.; Fujihara, T.; Tsuji, Y. J. Am. Chem. Soc. 2014, 136, 14714.

(9) For examples of stimuli responsive main chain poly[n]rotaxanes see: (a) Gibson, H. W.; Shen, Y. X.; Bheda, M. C.; Gong, C. Polym. 2014, 55, 3202; (b) Gong, C.; Gibson, H. Angew. Chem., Int Ed. 1997, No. 21, 2331; (c) Fujita, H.; Ooya, T.; Yui, N. Macromolecules 1999, 32, 2534; (d) Ogoshi, T.; Nishida, Y.; Yamagishi, T.; Nakamoto, Y. Macromolecules 2010, 43, 7068.

(10) For selected examples of main chain polyrotaxane-based sensors see: (a) Zhu, S. S.; Carroll, P. J.; Swager, T. M. J. Am. Chem. Soc. 1996, 118, 8713; (b) Kwan, P. H.; MacLachlan, M. J.; Swager, T. M. J. Am. Chem. Soc. 2004, 126, 8638. 
(11) For selected examples of slide-ring polymer gels see: (a) Okumura, Y.; Ito, K. Adv. Mat. 2001, 8656, 485; (b) Sakai, T.; Murayama, H.; Nagano, S.; Takeoka, Y.; Kidowaki, M.; Ito, K.; Seki, T. Adv. Mater. 2007, 19, 2023; (c) Ito, K. Polym. J. 2007, 39, 489; (d) Araki, J.; Ito, K. Soft Matter 2007, 3, 1456; (e) Kato, K.; Inoue, K.; Kidowaki, M.; Ito, K. Macromolecules 2009, 42, 7129; (f) Ito, K. Curr. Opin. Solid State Mater. Sci. 2010, 14, 28; (g) Kato, K.; Okabe, Y.; Okazumi, Y.; Ito, K. Chem. Commun. 2015, 51, 16180; (h) Kato, K.; Mizusawa, T.; Yokoyama, H.; Ito, K. J. Phys. Chem. Lett. 2015, 6,4043 .

(12) The terms "homocircuit" and "heterocircuit" have been used previously to describe catenanes and Borromean rings composed of constitutionally identical or different macrocycles respectively (see ref. 2c and: (a) Kidd, T. J.; Leigh, D. A.; Wilson, A. J. J. Am. Chem. Soc. 1999, 121, 1599. (b) Beves, J. E.; Blight, B. A.; Campbell, C. J.; Leigh, D. A.; McBurney, R. T. Angew. Chem. Int Ed. 2011, 50, 9260). Here we apply these terms descriptively to distinguish between [n]rotaxanes composed of multiple identical macrocycles or two or more different macrocycles. In terms of nomenclature, these molecules are simply referred to as homo- and hetero-[n]rotaxanes respectively and we use this convention when naming compounds.

(13) Solvophobic threading of macrocycles onto block copolymers has been shown to lead to block-selective recognition (for examples see: (a) Li, J.; Ni, X.; Leong, K. Angew. Chem. Int. Ed. 2003, 42, 69. (b) Choi, H. S.; Ooya, T.; Sasaki, S.; Yui, N.; Ohya, Y.; Nakai, T.; Ouchi, T. Macromolecules 2003, 36, 9313. (c) Li, J.; Ni, X.; Zhou, Z.; Leong, K. W. 2003, 1788. (d) Chen, J.; Li, N.; Gao, Y.; Sun, F.; He, J.; Li, Y. Soft Matter 2015, 11, 7835.) and would seem a logical approach to the synthesis of ordered polymeric hetero[n]rotaxanes. However, to our knowledge this approach has not been realized to date.

(14) For an example of a random hetero[n]rotaxane produced by threading of two distinct $\alpha$-CD derivatives onto a preformed polymeric axle see: Tamura, M.; Gao, D.; Ueno, A. J. Chem. Soc. Perkin Trans. 2 2001, 2012.

(15) For an example of polymeric hetero[n]rotaxanes containing $\beta$ and $\gamma$-CD see: Herrmann, W.; Schneider, M.; Wenz, G. Angew. Chem. Int. Ed. English 1997, 36, 2511.

${ }^{16}$ The exception to this is the "cooperative capture" approach (Hou, X.; Ke, C.; Fraser Stoddart, J. Chem. Soc. Rev. 2016, 45, 4) to poly[n]rotaxanes developed by Stoddart and co-workers, which combines solvophobic threading, cooperative interactions between cucurbit[6]uril $(\mathrm{CB}[6])$ and $\beta$-cyclodextrin $(\beta-\mathrm{CD})$, and an alkyne-azide cycloaddition reaction mediated by $\mathrm{CB}[6]$ to produce hetero[n]rotaxanes with $100 \%$ threading ratio and perfectly alternating $\beta$ $\mathrm{CD}$ and $\mathrm{CB}[6]$ macrocycles: Ke, C.; Smaldone, R. A.; Kikuchi, T.; Li, H.; Davis, A. P.; Stoddart, J. F. Angew. Chem. Int. Ed. 2013, 52, 381. For an example of the attempted synthesis of hetero[3]rotaxanes through similar complementary interactions between macrocycles see: Wilson, E. A.; Vermeulen, N. A.; McGonigal, P. R.; Avestro, A.-J.; Sarjeant, A. A.; Stern, C. L.; Stoddart, J. F. Chem. Commun. 2014, 50, 9665.

(17) For selected examples of main chain poly[n]rotaxanes synthesized using specific templating interactions see: (a) Zhang, W.; Dichtel, W. R.; Stieg, A. Z.; Benitez, D.; Gimzewski, J. K.; Heath, J. R.; Stoddart, J. F. Proc. Natl. Acad. Sci. 2008, 105, 6514; (b) Gibson, H. W.; Wang, H.; Niu, Z.; Slebodnick, C.; Zhakharov, L. N.; Rheingold, A. L. Macromolecules 2012, 45, 1270; (c) Belowich, M. E.; Valente, C.; Smaldone, R. A.; Friedman, D. C.; Thiel, J.; Cronin, L.; Stoddart, J. F. J. Am. Chem. Soc. 2012, 134, 5243; (d) Han, J. M.; Zhang, Y. H.; Wang, X. Y.; Liu, C. J.; Wang, J. Y.; Pei, J. Chem. Eur. J. 2013, 19, 1502; (e) Kang, S.; Cetin, M. M.; Jiang, R.; Clevenger, E. S.; Mayer, M. F. J. Am. Chem. Soc. 2014, 136, 12588; (f) Nakazono,
K.; Ishino, T.; Takashima, T.; Saeki, D.; Natsui, D.; Kihara, N.; Takata, T. Chem. Commun. 2014, 50, 15341.

(18) (a) Badi, N.; Lutz, J.-F. Chem. Soc. Rev. 2009, 38, 3383; (b) Lutz, J.-F.; Ouchi, M.; Liu, D. R.; Sawamoto, M. Science 2013, 341, 1238149 .

(19) (a) Merrifield, R. B. J. Am. Chem. Soc. 1963, 85, 2149; (b) Beaucage, S. L.; Caruthers, M. H. Tetrahedron Lett. 1981, 22, 1859; (c) Caruthers, M. H. Science 1985, 230, 281; (d) Seeberger, P. H.; Haase, W.-C. Chem. Rev. 2000, 100, 4349; (e) Al Ouahabi, A.; Charles, L.; Lutz, J. F. J. Am. Chem. Soc. 2015, 137, 5629.

(20) For examples of iterative methods for the synthesis of interlocked molecules see: (a) Daniell, H. W.; Klotz, E. J. F.; Odell, B.; Claridge, T. D. W.; Anderson, H. L. Angew. Chem., Int. Ed. 2007, 46, 6845; (b) Spruell, J. M.; Dichtel, W. R.; Heath, J. R.; Stoddart, J. F. Chem. Eur. J. 2008, 14, 4168; (c) Fuller, A.-M. L.; Leigh, D. A.; Lusby, P. J. J. Am. Chem. Soc. 2010, 132, 4954; (d) Langton, M. J.; Matichak, J. D.; Thompson, A. L.; Anderson, H. L. Chem. Sci. 2011, 2, 1897; (e) Yamada, Y.; Okada, M.-A.; Tanaka, K. Chem. Commun. 2013, 49, 11053; (f) Heinrich, T.; Traulsen, C. H. H.; Holzweber, M.; Richter, S.; Kunz, V.; Kastner, S. K.; Krabbenborg, S. O.; Huskens, J.; Unger, W. E. S.; Schalley, C. A. J. Am. Chem. Soc. 2015, 137, 4382; (g) Wang, W.; Chen, L.-J.; Wang, X.-Q.; Sun, B.; Li, X.; Zhang, Y.; Shi, J.; Yu, Y.; Zhang, L.; Liu, M.; Yang, H.-B. Proc. Natl. Acad. Sci. 2015, 112, 5597; (h) Neal, E. A.; Goldup, S. M. Angew. Chem. Int. Ed. 2016, 55, 12488.

(21) (a) Rostovtsev, V. V.; Green, L. G.; Fokin, V. V.; Sharpless, K. B. Angew. Chem., Int. Ed. 2002, 41, 2596; (b) Tornøe, C. W.; Christensen, C.; Meldal, M. J. Org. Chem. 2002, 67, 3057.

(22) For recent reviews of the CuAAC reaction in multicomponent synthesis see: (a) Meldal, M.; Tornøe, C. W. Chem. Rev. 2008, 108, 2952; (b) Johnson, J. A.; Finn, M. G.; Koberstein, J. T.; Turro, N. J. Macromol. Rapid Commun. 2008, 29, 1052; (c) Hassan, S.; Müller, T. J. J. Adv. Synth. Catal. 2015, 357, 617; (c) Castro, V.; Rodríguez, H.; Albericio, F. ACS Comb. Sci. 2016, 18, 1.

(23) For selected examples of the iterative CuAAC reaction in synthesis see: (a) Angelo, N. G.; Arora, P. S. J. Am. Chem. Soc. 2005 127, 17134; (b) Such, G. K.; Quinn, J. F.; Quinn, A.; Tjipto, E.; Caruso, F. J. Am. Chem. Soc. 2006, 128, 9318; (c) Vestberg, R.; Malkoch, M.; Kade, M.; Wu, P.; Fokin, V. V.; Barry Sharpless, K.; Drockenmuller, E.; Hawker, C. J. J. Polym. Sci. Part A: Polym. Chem. 2007, 45, 2835; (d) Li, Y.; Flood, A. H. Angew. Chem. Int. Ed. 2008, 47, 2649; (e) Juwarker, H.; Lenhardt, J. M.; Pham, D. M.; Craig, S. L. Angew. Chem. Int. Ed. 2008, 47, 3740; (f) Meudtner, R. M.; Hecht, S. Angew. Chem. Int. Ed. 2008, 47, 4926; (g) Luo, L.; Frisbie, C. D. J. Am. Chem. Soc. 2010, 132, 8854; (h) Hua, Y.; Ramabhadran, R. O.; Karty, J. A.; Raghavachari, K.; Flood, A. H. Chem. Commun 2011, 47, 5979; (i) Ehlers, I.; Maity, P.; Aubé, J.; König, B. European J. Org. Chem. 2011, 2474; (j) Ingale, S. A.; Seela, F. J. Org. Chem. 2013, 78, 3394; Lewandowski, B.; De Bo, G.; Ward, J. W.; Papmeyer, M.; Kuschel, S.; Aldegunde, M. J.; Gramlich, P. M. E.; Heckmann, D.; Goldup, S. M.; D’Souza, D. M.; Fernandes, A. E.; Leigh, D. A. Science 2013, 339, 189; (k) Galibert, M.; Piller, V.; Piller, F.; Aucagne, V.; Delmas, A. F. Chem. Sci. 2015, 3617; (1) Shang, J.; Zhao, W.; Li, X.; Wang, Y.; Jiang, H. Chem. Commun. 2016, 52, 1; (m) Zurro, M.; Asmus, S.; Bamberger, J.; Beckendorf, S.; García Mancheño, O. Chem. Eur. J. 2016, 22, 3785.

(24) For examples of iterative synthesis of triazole oligomers see: (a) Barnes, J. C.; Ehrlich, D. J. C.; Gao, A. X.; Leibfarth, F. A.; Jiang, Y.; Zhou, E.; Jamison, T. F.; Johnson, J. A. Nat. Chem. 2015, 7, 810. (b) Jiang, Y.; Golder, M. R.; Nguyen, H. V.-T.; Wang, Y.; Zhong, M.; Barnes, J. C.; Ehrlich, D. J. C.; Johnson, J. A. J. Am. Chem. Soc. 2016, 138, 9369. 
(25) For examples of iterative CuAAC methodologies see: (a) Lu, G.; Lam, S.; Burgess, K. Chem. Commun. 2006, 1652; (b) Aucagne, V.; Leigh, D. A. Org. Lett. 2006, 8, 4505; (c) Kaliappan, K. P.; Kalanidhi, P.; Mahapatra, S. Synlett 2009, 2162; (d) Valverde, I. E.; Delmas, A. F.; Aucagne, V. Tetrahedron 2009, 65, 7597; (e) Stefani, H. A.; Canduzini, H. A.; Manarin, F. Tetrahedron Lett. 2011, 52, 6086; (f) Aizpurua, J. M.; Sagartzazu-Aizpurua, M.; Azcune, I.; Miranda, J. I.; Monasterio, Z.; García-Lecina, E.; Fratila, R. M. Synthesis 2011, 2737; (g) Yuan, Z.; Kuang, G.-C.; Clark, R. J.; Zhu, L. Org. Lett. 2012, 14, 2590. (h) Ingale, S. A.; Seela, F. J. Org. Chem. 2013, 78, 3394. (i) Pancholi, J.; Hodson, D. J.; Jobe, K.; Rutter, G. A.; Goldup, S. M.; Watkinson, M. Chem. Sci. 2014, 5, 3528; (j) Hatit, M. Z. C.; Sadler, J. C.; McLean, L. A.; Whitehurst, B. C.; Seath, C. P.; Humphreys, L. D.; Young, R. J.; Watson, A. J. B.; Burley, G. A. Org. Lett. 2016, 18, 1694.

(26) For an alternative methodology that combines iterative amide bond formation with the CuAAC reaction see: Holub, J. M.; Jang, H.; Kirshenbaum, K. Org. Biomol. Chem. 2006, 4, 1497.

(27) (a) Aucagne, V.; Hänni, K. D.; Leigh, D. A.; Lusby, P. J.; Walker, D. B. J. Am. Chem. Soc. 2006, 128, 2186. (b) Aucagne, V.; Berna, J.; Crowley, J. D.; Goldup, S. M.; Hänni, K. D.; Leigh, D. a; Lusby, P. J.; Ronaldson, V. E.; Slawin, A. M. Z.; Viterisi, A.; Walker, D. B. J. Am. Chem. Soc. 2007, 129, 11950.

(28) (a) Lahlali, H.; Jobe, K.; Watkinson, M.; Goldup, S. M. Angew. Chem., Int. Ed. 2011, 50, 4151. (b) Winn, J.; Pinczewska, A.; Goldup, S. M. J. Am. Chem. Soc. 2013, 135, 13318. (c) Bordoli, R. J.; Goldup, S. M. J. Am. Chem. Soc. 2014, 136, 4817. (d) Neal, E. A.; Goldup, S. M. Chem. Sci. 2015, 6, 2398. (e) Galli, M.; Lewis, J. E. M.; Goldup, S. M. Angew. Chem. Int. Ed. 2015, 54, 13545. (f) Lewis, J. E. M.; Bordoli, R. J.; Denis, M.; Fletcher, C. J.; Galli, M.; Neal, E. A.; Rochette, E. M.; Goldup, S. M. Chem. Sci. 2016, 7, 3154.

(29) For a review of the active template approach more generally see: Crowley, J. D.; Goldup, S. M.; Lee, A.-L.; Leigh, D. A; McBurney, R. T. Chem. Soc. Rev. 2009, 38, 1530.

(30) Other metal-mediated bond formations have been adapted for the active template synthesis of interlocked molecules. For selected examples see: (a) Saito, S.; Takahashi, E.; Nakazono, K. Org. Lett. 2006, 8, 5133; (b) Berná, J.; Crowley, J. D.; Goldup, S. M.; Hänni, K. D.; Lee, A.-L.; Leigh, D. A. Angew. Chem., Int. Ed. 2007, 46, 5709; (c) Crowley, J. D.; Hänni, K. D.; Lee, A.; Leigh, D. A. J. Am. Chem. Soc. 2007, 129, 12092; (d) Berná, J.; Goldup, S. M.; Lee, A.-L.; Leigh, D. A.; Symes, M. D.; Teobaldi, G.; Zerbetto, F. Angew. Chem. Int. Ed. 2008, 47, 4392; (e) Crowley, J. D.; Goldup, S. M.; Gowans, N. D.; Leigh, D. A.; Ronaldson, V. E.; Slawin, A. M. Z. J. Am. Chem. Soc. 2010, 132, 6243; (f) Crowley, J. D.; Hänni, K. D.; Leigh, D. A.; Slawin, A. M. Z. J. Am. Chem. Soc. 2010, 132, 5309; (g) Crowley, J. D.; Goldup, S. M.; Gowans, N. D.; Leigh, D. a; Ronaldson, V. E.; Slawin, A. M. Z. J. Am. Chem. Soc. 2010, 132, 6243; (h) Ugajin, K.; Takahashi, E.; Yamasaki, R.; Mutoh, Y.; Kasama, T.; Saito, S. Org. Lett. 2013, 15, 2684; (i) Cheng, H. M.; Leigh, D. A.; Maffei, F.; McGonigal, P. R.; Slawin, A. M. Z.; Wu, J. J. Am. Chem. Soc. 2011, 133, 12298; (j) Langton, M. J.; Xiong, Y.; Beer, P. D. Chem. - A Eur. J. 2015, 21, 18910 .

(30) Heating in an oil bath gave similar isolated yields of the target rotaxanes. However microwave irradiation was more operationally convenient as it ensures accurate heating and thus reproducible reaction times, as well as being more energy efficient.

(32) Modelling was carried out using Spartan '10 (Wavefunction Inc.). Rotaxanes 6 (syn-syn, syn-anti, and anti-anti conformations), 13 and 18 were modelled using semi-empirical methods (PM6). The noninterlocked axle of rotaxane 6 was modelled using DFT (B3LYP, 6$\left.31 \mathrm{G}^{*}\right)$. For full details see the supporting information.
(33) A small number of solid state structures for $N, N$ '-aryl meta bis-triazole benzenes similar to the non-interlocked axle of $\mathbf{6}$ have been reported, all but one of which (ref. 31b) exhibit syn-anti or antianti conformations in the solid state. However, given that all examples feature close inter-molecular contacts and, in many cases, $\mathrm{H}$ bonding interactions with co-crystalized solvent, it is perhaps unwise to extrapolate from these solid state structures to the solution state conformations of these molecules: (a) García, F.; Torres, M. R.; Matesanz, E.; Sánchez, L. Chem. Commun. 2011, 47, 5016; (b) White, N. G.; Beer, P. D. Supramol. Chem. 2012, 24, 473; (c) Asmus, S.; Beckendorf, S.; Zurro, M.; Mück-Lichtenfeld, C.; Fröhlich, R.; García Mancheño, O. Chem. Asian J. 2014, 9, 2178.

(34) Wherever possible, signals are coloured according to the component they are derived from, as in the relevant reaction scheme. However, in the case of complex multiplets derived from multiple components the colour coding is indicative only. See supporting information for detailed assignments of signals.

(35) Clayden, J. Chem. Soc. Rev. 2009, 38, 817.

(36) In review it was suggested, that given the excellent yields achieved over each chain elongation sequence, it might be possible to carry out the reactions described above without purification between the deprotection and AT-CuAAC steps. Although this is extremely synthetically attractive, the presence of TBAF and other tetrabutyl ammonium salts that are incompletely removed during aqueous workup can interfere with the AT-CuAAC reaction. Furthermore, even minor quantities of "defective" chains, particularly in the case of heterocircuit structures, amplified over many rounds of AT-CuAAC reaction, would be extremely difficult to separate. Reactions on solid support solve both of these problems by allowing excess reagents to be used and removed at each step. An alternative suggestion was to do away with protecting groups altogether (which would circumvent some of the above issues) by relying on steric control in the reaction of diyne $\mathbf{1}$ and its di-azide counterpart. Sadly this isn't possible in the current system; simple molecular models reveal the azide functional group is not sufficiently bulky to prevent the macrocycle escaping the axle in the AT-CuAAC products of these monomers. This is however and excellent alternative approach and we are actively investigating how it could be achieved with different monomers.

(37) The CuAAC reaction has already been demonstrated to be an effective tool in solid phase synthesis. ${ }^{21,24 d, 25}$. 


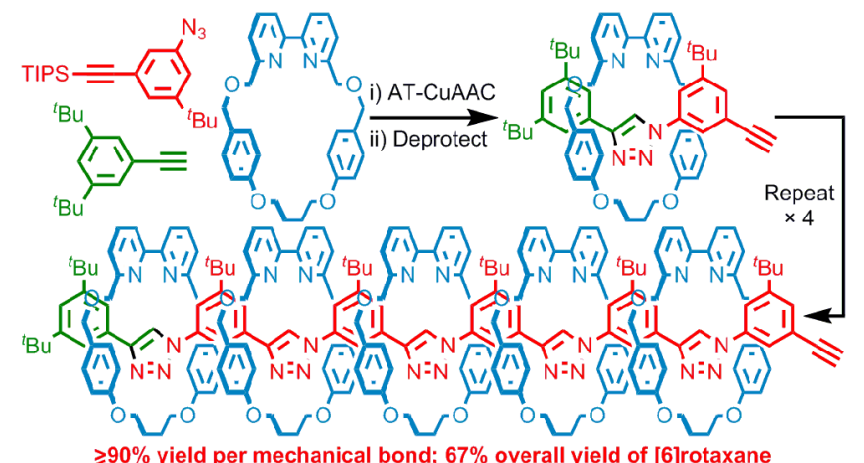

